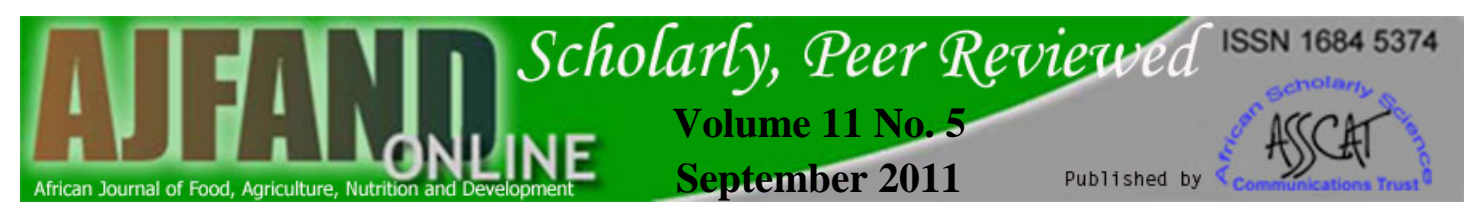

\title{
USE AND UNDERSTANDING OF NUTRITION LABELS AMONG CONSUMERS IN LILONGWE (MALAWI)
}

\section{Kasapila $\mathrm{W}^{1} *$ and $\mathbf{P}$ Shawa ${ }^{1}$}

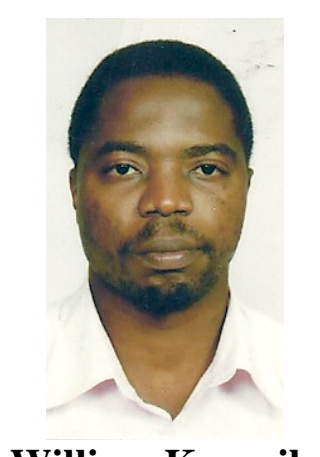

\section{William Kasapila}

*Corresponding Author’s Email: wkasapila@yahoo.co.uk

${ }^{1}$ University of Malawi, Bunda College of Agriculture, Home Economics and Human Nutrition Department, P.O. Box 219, Lilongwe, Malawi. 


\section{ABSTRACT}

This study investigated use and understanding of nutrition labels on food packages among urban and rural consumers in Lilongwe (Malawi). It also examined the effect of socio-demographic factors and nutrition knowledge on use of nutrition labels. The study surveyed 206 consumers, approached randomly after they checked out at grocery stores. Shop managers and owners gave their consent to conduct the study outside the shops to avoid affecting customer behaviour and revenues. A pre-tested questionnaire was used to collect data for analysis and interpretation. The questionnaire was formulated based on questionnaires validated and used reliably in previous studies. The findings show that self-reported use and understanding of nutrition labels were low, suggesting much lower use and comprehension in real-life retail environments. Urban consumers were more likely to read nutrition panels when purchasing food than rural consumers $\left(\chi^{2}=44.058, \mathrm{df}=1, \mathrm{p}=0.000\right)$. Similarly, educated $\left(\chi^{2}=68.681, \mathrm{df}=3, p=0.000\right)$ and female consumers $\left(\chi^{2}=8.915, \mathrm{df}=1, p=0.003\right)$ were more inclined to consult nutrition labels than the other consumers. Nutrition labels were seen as important, particularly when purchasing a product for the first time and when considering buying certain products. All label users $(n=60)$ were interested in information about fat, salt, sugar, vitamins and minerals. Besides nutrition information, prices and taste were important considerations in consumers' food choices. In terms of nutrition knowledge, rural consumers were as knowledgeable $(\mu=9.55)$ as urban consumers $(\mu=9.99)$, but they were less likely to connect their knowledge to emerging non-communicable diseases, such as cancer and coronary heart disease, than were urban consumers. Despite these findings, the study had some limitations. For example, the researchers surveyed a small sample of shoppers drawn from one geographical area. As such, the findings obtained are suggestive rather than conclusive. Objective, cross-sectional and longitudinal investigations in future would improve our understanding of actual consumer behaviour in retail shops, and homes in Malawi. Conversely, this study is the first of its kind in Malawi. Therefore, it provides baseline information useful to the healthcare professionals, the government, the food industry and consumers.

Key words: Nutrition, Labels, Consumers, Foods, Malawi 


\section{INTRODUCTION}

The development of global supermarkets is bringing a plethora of new pre-packaged foods to the developing nations. Many consumers discover these foods displayed in stores, but they cannot taste or smell the products before purchase. Nutrition labelling educates them about what they are buying and eating [1]. It also allows consumers to make informed choices based on safety, cultural, ethical, religious and dietary concerns [2, 3]. In view of the unprecedented importance of nutrition labels, debates are progressive, ongoing and inconclusive at international, regional and national levels regarding what goes into the label, format, verifiability, size, impact and authority [4]. Different groups have argued for their concerns to be labelled: ingredients, residues, animal welfare, allergens, environmental impact, nutrition, ethics and others [4]. For countries in sub-Saharan Africa, nutrition labelling has become a core policy issue in view of emerging diet-related diseases (such as diabetes, coronary heart disease and cancer) which are fast becoming a big threat to public health as reported by the World Health Organisation [5].

In Malawi, food and nutrition labelling is under the jurisdiction of Malawi Bureau of Standards (MBS) and Ministry of Health [6, 7]. Presently, MBS has two standards which regulate nutrition labelling and claims on food meant for adults; namely, MS 624:2001 and MS 625:2001 [6]. These standards are an adoption of the Codex Alimentarius Guidelines on nutrition labelling (CAC/GL 2-1985), and Guidelines for Nutrition and Health Claims (CAC/GL 1-1979; Rev. 1-1991) [8, 9]. The Ministry of Health regulates the manufacturing and marketing of infant and young children's foods through the Public Health Act (Cap 34:01). These foods include, but are not limited to, corn and soy flours, infant formulas, milk products, fruit juices, margarine and cooking oils, peanut butters and various types of drinks and snacks [7]. Generally, regulations in Malawi require the food industry to declare energy, protein, carbohydrate and fat content for any pre-packaged foods for which nutrition claims are made [6]. In line with the Codex Guidelines, the regulations also require nutrition labels and claims to be consistent with national policies on health, supported by a sound body of scientific evidence, and to provide truthful information to help consumers choose healthful diets [8, 9]. The Codex Alimentarius is a joint FAO/WHO intergovernmental body whose standards, codes and related texts are recognised and followed worldwide [10].

Despite efforts to regulate nutrition labelling, it is not known if consumers use the information on food packages. The literature reveals no documented study in Malawi regarding consumers' use and understanding of nutrition information. In sub-Saharan Africa, two studies were identified in Lesotho and South Africa [11, 12], in which $40.5 \%$ and $55 \%$ of food shoppers, respectively, reported reading nutrition labels in supermarkets. The present study focused on Malawi to answer the following questions: Do consumers read and understand on-pack nutrition information? How often do they read the labels? Which consumers are interested in food labels? What information are they interested in? How do non-label users make their food choices? What are the reasons for not using on-pack information? Answers to these questions

Published by African Scholarly Science Communications Trust
Josem Trust Place, Bunyala Road, Upper Hill, Nairobi
$\begin{aligned} & \text { P.O. Box 29086-00625 Tel: +254-20-2351785 Fax: }+254-20-4444030, \text { Nairobi, KENYA } \\ & \text { Email: oniango@iconnect.co.ke OR info@ajfand.net } \quad \text { www.ajfand.net }\end{aligned}$


would provide valuable and baseline information to healthcare professionals, researchers, policy makers and the food industry.

\section{METHODS}

\section{Sample and Sampling Procedure}

The study was conducted in Lilongwe district from October to November 2009 and engaged 104 urban and 102 rural consumers. Consumers, especially those 18 years and older, were approached at random after checkout and asked if they purchased any pre-packaged food and were willing to participate in this study. These consumers were considered old enough to make independent purchase decisions. Servants instructed to buy food were excluded from the study. The researchers recruited customers of Peacock and Peoples shops in the urban area and two local grocery stores in the rural area. Shop managers and owners gave their consent to conduct the study outside the shops to avoid affecting customer behaviour and revenues.

At recruitment, shoppers were told that there were no right or wrong answers in the task, and that the study aimed at exploring how people make their food choices. Shoppers recruited were not told about the specific objective of the study to minimize bias in their responses. At the end of the interviews, shoppers were informed that the study aimed at investigating use and understanding of nutrition information on food products. Data were collected at different times of the day, using a pre-tested questionnaire. The pre-test sample (10 urban and 12 rural shoppers) did not form part of the final sample for this study. Data entry and analysis were done in SPSS computer package [13]. Descriptive and inferential statistics were generated and used to describe and explain the findings.

\section{Measures}

The questionnaire for the study was formulated based on questionnaires used reliably in previous studies [14, 15, 16, 17]. Consumer behaviour in retail shops was measured through self-reported use and understanding of food nutrition labels, types of information read, and reasons for use and non-use of on-pack nutrition information. Also, the study measured consumer knowledge of dietary recommendations in relation to cancer and coronary heart disease. Codex Alimentarius, whose standards Malawi follows, requires that the nutrition information provided on pre-packaged foods be selected on the basis of consistency with dietary recommendations [8]. That is why the use and understanding of nutrition labels and knowledge of dietary recommendations were examined together in this study.

The original questionnaire on expert recommendations for healthy eating was validated in Britain [14]. These researchers pointed out that "a nutrition knowledge questionnaire developed in the Netherlands would not necessarily be valid for a UK population because of cultural variations in eating habits and precise dietary recommendations" [14]. Thus, items on dietary recommendations were adapted to suit the Malawian context. In Malawi, healthcare professionals emphasize eating more food in the following categories to fight under-nutrition particularly in rural areas: staples, fruits, vegetables, legumes, fibre foods, animal foods and fats and oils. 
Moreover, the experts promote low consumption of salty and sugary foods [18]. In this context, the respondents were asked to indicate whether experts recommend eating more, the same or less of nine items listed.

The researchers also examined consumers' knowledge of the relationships between diet and cancer (six items) and coronary heart disease (five items). The respondents answered the following questions:

- Do you think the following dietary behaviours help to reduce the chances of getting certain types of cancer: eating more fibre, less sugar, less fruit, less salt, more fruits and vegetables, and less preservatives or additives?

- Do you think the following help prevent coronary heart disease: eating more fibre, less saturated fat, less salt, more fruits and vegetables, and less preservatives or additives?

The respondents indicated "yes," "no," or "not sure" on each of the dietary behaviours provided. The socio-demographic information of the respondents (age, sex, education, employment and marital status) also was obtained.

\section{RESULTS}

\section{Socio-demographic Information of the Sample}

The majority of the respondents were male (57.3\%), aged between 18-30 years $(60.7 \%)$ and married (58.7\%). The majority of urban consumers had secondary (36.5\%) or post-secondary education (54.8\%) and were employed $(69.2 \%)$ unlike their rural counterparts. Further details for socio-demographic characteristics of the respondents are presented in Table 1.

\section{Use and Understanding of Nutrition Labels in Grocery Stores}

Less than one third (29.1\%) of the respondents reported reading on-pack nutrition information in grocery stores (Table 2). Urban consumers $(52.9 \%)$ were more likely to read nutrition labels than their rural (4.9\%) counterparts $\left(\chi^{2}=44.058, \mathrm{df}=1\right.$, $p=0.000)$. Consumers with post-secondary education $\left(\chi^{2}=68.681, \mathrm{df}=3, p=0.000\right)$ and females $\left(\chi^{2}=8.915, \mathrm{df}=1, p=0.003\right)$ were also more inclined to consult nutrition panels before purchasing food than the other consumers. Among all label users $(n=60), 7.3 \%$ reported to understand well what they read on the nutrition panel, 18.9\% understood it partly and the rest (73.8\%) did not understand the numerical information and terminology used (Table 2). Moreover, the rural consumers were not familiar with the English language (64.3\%) on food packages. Figure 1 shows an example of a nutrition panel, used on food products in Malawi, which consumers find difficult to understand. 


\begin{tabular}{|l|c|c|}
\hline \multicolumn{3}{|c|}{ NUTRITIONAL INFORMATION } \\
Servings per package: 72 approximately \\
Serving size: 1 biscuit (approximately 3.6g) \\
\hline & Per Serving & Per \\
& $3.6 \mathrm{~g}$ & $100 \mathrm{~g}$ \\
\hline Energy & $69.0 \mathrm{~kJ}$ & $1923 \mathrm{~kJ}$ \\
Protein & $0.3 \mathrm{~g}$ & $9.6 \mathrm{~g}$ \\
Fat & $0.6 \mathrm{~g}$ & $17.4 \mathrm{~g}$ \\
Carbohydrate & & \\
- total & $2.4 \mathrm{~g}$ & $69.2 \mathrm{~g}$ \\
- sugars & $0.07 \mathrm{~g}$ & $2.0 \mathrm{~g}$ \\
Dietary fibre & $0.10 \mathrm{~g}$ & $3.0 \mathrm{~g}$ \\
Sodium & $24.0 \mathrm{mg}$ & $676 \mathrm{mg}$ \\
Potassium & $5.2 \mathrm{mg}$ & $147 \mathrm{mg}$ \\
\hline
\end{tabular}

\section{Figure 1: An example of a nutrition panel used on food products in Malawi}

On the whole, nutrition labels were considered important when purchasing a product for the first time or when considering buying certain foods: for example, milk and milk products, fats and oils, and soft drinks (Table 3). Generally, urban consumers looked for fat content in foods, along with salt and sugar, while rural consumers were interested in vitamins and minerals, particularly vitamin A, iron and iodine (Table 3). Besides nutrition information, consumers were influenced by food prices and taste and, to a lesser extent, product weight, "best before" or "use by" dates, and the ingredient list at the point-of-purchase (Table 4). One in every ten consumers (8.8\%) described the information on food packages as exaggerated and dubious. In other words, these consumers viewed food and nutrition labels as attempts by food manufacturers to sell more products rather than provide health information to the public.

\section{Nutrition Knowledge among Respondents}

Overall, rural consumers were as knowledgeable $(\mu=9.55)$ as urban consumers $(\mu=9.99)$ as regards nutrition. In terms of individual components examined, rural consumers had more knowledge about dietary recommendations in Malawi than their urban counterparts $(\mathrm{t}=-4.933, p=0.000)$. Conversely, urban consumers showed better understanding of the relationships between diet and cancer $(\mathrm{t}=4.560, p=0.000)$ and coronary heart disease $(\mathrm{t}=3.309, p=0.001)$ than did rural consumers (Table 5). Females were more familiar with diet and disease relationships than males $(\mathrm{t}=-4.963$, $p=0.000$ ). Generally, consumers could not associate high salt intake with the risk of getting cancer and they could hardly link food additives to cancer and heart disease. Correlation analyses revealed that interest to read nutrition labels tended to increase with increase in knowledge of heart disease $(\mathrm{r}=0.498, p=0.000)$ and cancer $(\mathrm{r}=0.525$, $p=0.000)$. 


\section{DISCUSSION}

This study found low use (29.1\%) and understanding (26.2\%) of nutrition labels among consumers in Lilongwe (Malawi), which suggests much lower use and comprehension in real-life retail environments. Consumers were not conversant with the numeracy, terminology and language on the current nutrition panel, pointing towards the need for basic nutrition education and user-friendly label formats. Figures as low as these (or lower) also have been reported in studies worldwide [11, 17, 18, 19, 20, 21]. A recent multi-country study involving the UK, Sweden, Germany, France, Poland and Hungary found that only $16.8 \%$ of the shoppers read nutrition panels, and understanding of nutrition information was limited in the three last countries [17]. Unlike findings of the present study, consumers in the UK, Sweden and Germany understood nutrition labels quite well, but they had no motivation to consult labels when purchasing food. Conversely, the percentages reporting to check on-pack nutrition information are higher in other studies; for instance, 55\% in South Africa, 58\% in the UK, 65\% in Ireland, and 66\% for the 2008 ACNielsen global study that polled consumers from 51 countries [12, 15, 22, 23]. One must interpret these findings cautiously in view of the different methodologies used across countries and studies.

It was hypothesised that the use of nutrition labels would differ among consumers following their discrepancies in socio-demographic factors and interest in healthy eating. The pre-suppositions were supported and confirmed. Urban consumers with post-secondary education were more inclined to read nutrition labels than rural consumers $\left(\chi^{2}=44.058, \mathrm{df}=1, \mathrm{p}=0.000\right)$. Drichoutis et al. point out that consumers with lower education and income levels (such as rural consumers in this study) attach importance to price and are usually less likely to use labels [24]. Among the educated consumers of this study, women were more likely to consult nutrition labels when purchasing food products than men and they also demonstrated better knowledge of nutrition than men. Similar findings were reported by different authors in the USA, Asia and the UK [15, 25, 26, 27]. Men are less likely to agree that nutrition information on food packages is useful and, therefore, are less interested in nutrition and health than women [24]. Despite this, nutrition labels are meant for all consumers: rich and poor; male and female.

Rural consumers, whose majority had low educational levels, were as knowledgeable about nutrition $(\mu=9.55)$ as urban consumers $(\mu=9.99)$. However, this did not apply to the individual areas examined. For instance, rural consumers showed better knowledge of dietary recommendations in Malawi $(\mathrm{t}=-4.933$, $\mathrm{df}=158, p=0.000)$, but they had lower scores for the relationships between diet and cancer $(\mathrm{t}=4.560, \mathrm{df}=158$, $p=0.000)$ and coronary heart disease $(\mathrm{t}=3.309, \mathrm{df}=158, p=0.001)$ than urban consumers. While these findings reflect the positive impact of intervention programs, particularly in rural Malawi, they imply that the dietary lessons have little, if any, focus on such emerging chronic diseases as cancer and heart disease. Instead, emphasis seems to be on dietary diversification to fight under-nutrition. In spite of this, WHO reports that close to $80 \%$ of the non-communicable disease (NCD) burden is now found in developing countries, involving lower socio-economic groups [5]. 
This is attributed to obstacles such as seeing the emerging NCDs as "diseases of affluence”, powerful commercial interests that block policies and generate conflicting messages, and traditional training of health personnel that emphasizes curative rather than preventive care [5].

The researchers acknowledge some limitations in this study. For example, the sample size of 206, which was drawn from one geographical area, limits generalisation of the findings. Thus, the findings are suggestive rather than conclusive. Besides this, the study relied on self-reports to investigate consumer use and understanding of food labels in grocery stores. Therefore, it is possible that the respondents reported intended rather than actual shopping behaviours. Moreover, the researchers found only two publications on nutrition labelling in sub-Saharan Africa for studies conducted in Lesotho and South Africa [11, 12]. For this reason, the findings of this study were compared to the findings of studies conducted in developed countries, whose consumers are far much savvier than those in Malawi. Lastly, this study focused on adults in the general population, probably at the expense of the young, minority groups and people who have specific diseases like diabetes mellitus, stroke, cancer and/or HIV/AIDS.

Despite these limitations, the findings of this study have several public health implications. First, the low use and understanding of nutrition information among consumers stresses the need for nutrition labels to be in simple, familiar and nontechnical language so that the majority of consumers can understand what they mean. For the average consumer from lower socio-economic groups, this may mean costeffective visual information such as a food pyramid graphic (used in the USA) or distinctive logos from retailers and charities, followed by basic nutrition education. Second, the cynicism and scepticism reported in this study (8.8\%) probably require approval statements from a regulatory body, such as Malawi Bureau of Standards (MBS), to endorse the scientific certainty and credibility of nutrition claims provided on food products. Third, the socio-demographic differences in consumer behaviour regarding nutrition labelling, diet and health can help healthcare professionals focus intervention programs on those most in need. Fourth, insufficient knowledge of cancer and heart disease, particularly among rural consumers, points out the need for concerted efforts to prevent these diseases.

\section{CONCLUSION}

This study found that the use and understanding of nutrition information on food packages are low among consumers in Lilongwe (Malawi), mainly due to hard-toread labels. Further investigations should be objective, cross-sectional and longitudinal to elicit comprehensive information about consumer behaviour in retail shops and homes. 
Table 1: Socio-demographic characteristics of the sample

\begin{tabular}{|c|c|c|c|c|c|c|}
\hline \multirow[t]{2}{*}{ Demographics } & \multicolumn{2}{|c|}{ Urban } & \multicolumn{2}{|c|}{ Rural } & \multicolumn{2}{|c|}{ Total } \\
\hline & $n=104$ & $\%$ & $n=102$ & $\%$ & $n=206$ & $\%$ \\
\hline \multicolumn{7}{|l|}{ Sex } \\
\hline Male & 61 & 58.7 & 57 & 55.9 & 118 & 57.3 \\
\hline Female & 43 & 41.3 & 45 & 44.1 & 88 & 42.7 \\
\hline \multicolumn{7}{|l|}{ Age } \\
\hline $18-30$ & 68 & 65.4 & 57 & 55.9 & 125 & 60.7 \\
\hline $31-50$ & 31 & 29.8 & 33 & 32.4 & 64 & 31.1 \\
\hline$\geq 51$ & 5 & 4.8 & 12 & 11.8 & 17 & 8.3 \\
\hline \multicolumn{7}{|l|}{ Education } \\
\hline None & 1 & 1 & 20 & 19.6 & 21 & 10.2 \\
\hline Primary & 8 & 7.7 & 66 & 64.7 & 74 & 35.9 \\
\hline Secondary & 38 & 36.5 & 14 & 13.7 & 52 & 25.2 \\
\hline Post secondary & 57 & 54.8 & 2 & 2 & 59 & 28.6 \\
\hline \multicolumn{7}{|l|}{ Employment status } \\
\hline Student & 5 & 4.8 & 0 & 0 & 5 & 2.4 \\
\hline Unemployed & 27 & 26 & 69 & 67.6 & 96 & 46.6 \\
\hline Employed & 72 & 69.2 & 33 & 32.4 & 105 & 51 \\
\hline \multicolumn{7}{|l|}{ Marital status } \\
\hline Single & 43 & 41.3 & 15 & 14.7 & 58 & 28.2 \\
\hline Married & 51 & 49 & 70 & 68.6 & 121 & 58.7 \\
\hline Separated/divorced & 10 & 9.6 & 17 & 16.7 & 27 & 13.1 \\
\hline
\end{tabular}




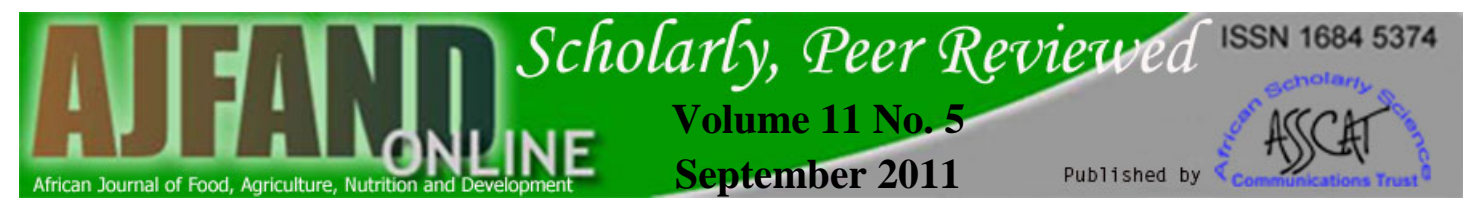

Table 2: Self--reported use and understanding of nutrition labels $(\mathrm{N}=\mathbf{2 0 6})$

\begin{tabular}{|c|c|c|c|c|c|c|}
\hline \multirow[t]{2}{*}{ Nutrition Label Use } & \multicolumn{2}{|c|}{ Urban } & \multicolumn{2}{|c|}{ Rural } & \multicolumn{2}{|c|}{ Total } \\
\hline & $n=104$ & $\%$ & $n=102$ & $\%$ & $n=206$ & $\%$ \\
\hline \multicolumn{7}{|l|}{ Do you read nutrition labels? } \\
\hline Yes & 55 & 52.9 & 5 & 4.9 & 60 & 29.1 \\
\hline No & 49 & 47.1 & 97 & 95.1 & 146 & 70.9 \\
\hline \multicolumn{7}{|l|}{ When do you read the labels? } \\
\hline When buying a product for the first time & 44 & 42.3 & 5 & 4.9 & 49 & 23.8 \\
\hline When buying certain foods & 32 & 30.8 & 3 & 2.9 & 35 & 17 \\
\hline When trying to lose weight & 8 & 7.7 & 0 & 0 & 8 & 3.9 \\
\hline When buying products for my family & 17 & 16.3 & 4 & 3.9 & 21 & 10.2 \\
\hline When comparing products & 7 & 6.7 & 2 & 2 & 9 & 4.4 \\
\hline Never read the labels & 49 & 47.1 & 97 & 95.1 & 146 & 70.9 \\
\hline \multicolumn{7}{|l|}{ Do you understand nutrition labels? } \\
\hline Yes & 49 & 47.1 & 5 & 4.9 & 54 & 26.2 \\
\hline No & 55 & 52.9 & 97 & 95.1 & 152 & 73.8 \\
\hline \multicolumn{7}{|l|}{ How is your understanding like? } \\
\hline Mostly understand & 12 & 11.5 & 3 & 2.9 & 15 & 7.3 \\
\hline Partly understand & 37 & 35.6 & 2 & 2 & 39 & 18.9 \\
\hline Don’t understand & 55 & 52.9 & 97 & 95.1 & 152 & 73.8 \\
\hline
\end{tabular}


Table 3: Products and nutrition information of concern among the label users $(\mathrm{N}=60)$

\begin{tabular}{|c|c|c|c|}
\hline Nutrition Label Use & $\begin{array}{l}\text { Urban } \\
n=55\end{array}$ & $\begin{array}{c}\text { Rural } \\
n=5\end{array}$ & $\begin{array}{l}\text { Total } \\
n=60\end{array}$ \\
\hline \multicolumn{4}{|c|}{ On which products do you read labels? } \\
\hline Milk and milk products & 44 & 0 & 44 \\
\hline Canned foods & 17 & 0 & 17 \\
\hline Confectionaries & 12 & 1 & 13 \\
\hline Breakfast cereals & 23 & 0 & 23 \\
\hline Salad dressings & 36 & 0 & 36 \\
\hline Soft drinks and juices & 33 & 1 & 33 \\
\hline Enriched foods & 27 & 5 & 32 \\
\hline Fats and oils & 41 & 3 & 44 \\
\hline Ready meals & 18 & 0 & 18 \\
\hline Never read the labels & 49 & 97 & 146 \\
\hline \multicolumn{4}{|c|}{ What information do you look for on labels? } \\
\hline Calories & 14 & 0 & 14 \\
\hline Fat (saturated fat, cholesterol) & 52 & 0 & 52 \\
\hline Total carbohydrate & 16 & 0 & 16 \\
\hline Sugars & 41 & 1 & 42 \\
\hline Protein & 12 & 2 & 14 \\
\hline Sodium & 49 & 3 & 52 \\
\hline Vitamins & 28 & 4 & 32 \\
\hline Minerals & 23 & 5 & 28 \\
\hline
\end{tabular}




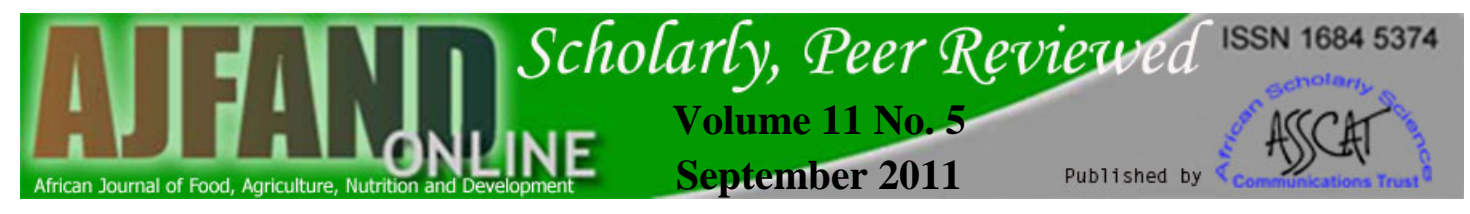

Table 4: Other factors affecting food choice at point of purchase

\begin{tabular}{|lcccccc|}
\hline Food Choice Factor & \multicolumn{2}{c}{ Urban } & \multicolumn{2}{c}{ Rural } & \multicolumn{2}{c|}{ Total } \\
& $\mathrm{n}=104$ & $\%$ & $\mathrm{n}=102$ & $\%$ & $\mathrm{n}=206$ & $\%$ \\
\hline Ingredients & 42 & 40.4 & 0 & 0 & 42 & 20.4 \\
Net weight or volume & 39 & 37.5 & 19 & 18.6 & 58 & 28.2 \\
Date marks & 25 & 24 & 18 & 17.6 & 43 & 20.9 \\
Taste & 57 & 54.8 & 60 & 58.8 & 117 & 56.8 \\
Price & 66 & 63.5 & 75 & 73.5 & 141 & 68.4 \\
Storage conditions & 7 & 6.7 & 4 & 3.9 & 11 & 5.3 \\
Instructions of use & 4 & 3.8 & 4 & 3.9 & 8 & 3.9 \\
\hline
\end{tabular}




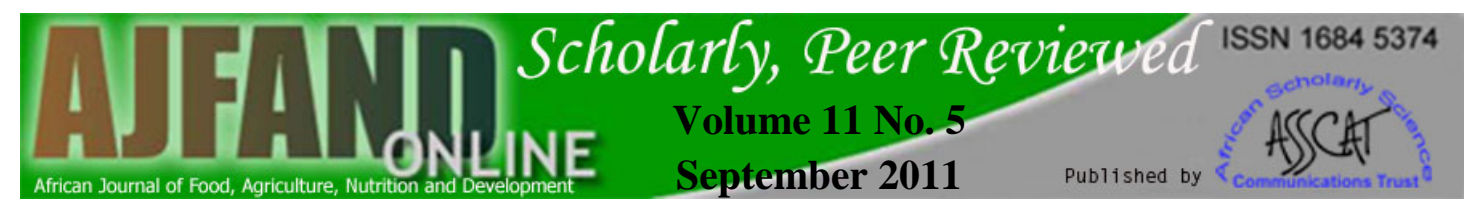

Table 5: Mean comparisons of nutrition knowledge by residence and gender

\begin{tabular}{|c|c|c|c|c|c|c|c|}
\hline \multirow{2}{*}{$\begin{array}{l}\text { Knowledge section } \\
\text { (maximum score) }\end{array}$} & \multicolumn{2}{|c|}{ Urban } & \multicolumn{2}{|c|}{ Rural } & \multirow[b]{2}{*}{ t-value } & \multirow[b]{2}{*}{ Df } & \multirow[b]{2}{*}{$p$-value } \\
\hline & Mean & SD* & Mean & SD & & & \\
\hline Expert recommendations (9) & 4.23 & 1.441 & 5.49 & 1.779 & -4.933 & 158 & 0.000 \\
\hline Diet-cancer relationship (6) & 2.90 & 1.673 & 1.81 & 1.323 & 4.560 & 158 & 0.000 \\
\hline Diet-heart disease (5) & 2.86 & 1.209 & 2.25 & 1.131 & 3.309 & 158 & 0.001 \\
\hline \multirow[t]{3}{*}{ Overall scores (20) } & 9.99 & 3.067 & 9.55 & 2.925 & 0.923 & 158 & 0.357 \\
\hline & \multicolumn{2}{|c|}{ Male } & \multicolumn{2}{|c|}{ Female } & & & \\
\hline & Mean & SD & Mean & SD & t-value & Df & $p$-value \\
\hline Expert Recommendations (9) & 4.96 & 1.735 & 4.72 & 1.735 & 0.850 & 158 & 0.396 \\
\hline Diet-cancer relationship (6) & 1.50 & 1.084 & 3.51 & 1.451 & -10.056 & 158 & 0.000 \\
\hline Diet-heart disease (5) & 2.37 & 1.202 & 2.81 & 1.175 & -2.307 & 158 & 0.022 \\
\hline Overall scores (20) & 8.83 & 2.696 & 11.04 & 2.924 & -4.963 & 158 & 0.000 \\
\hline
\end{tabular}

$* \mathrm{SD}=$ Standard deviation 


\section{REFERENCES}

1. Varma D Consumers and Nutritional Labelling: A Global Nielsen Report. 2008.

http://www.tr.nielsen.com/site/documents/nutritionalLabelingSep08_global_re port (accessed 14 March 2010).

2. Cowburn $\mathbf{G}$ and L Stockley Consumer Understanding and Use of Nutrition Labelling: A Systematic Review. Public Health Nutrition. 2005; 8: 21-28.

3. Grunert KG and JM Wills A Review of European Research on Consumer Response to Nutrition Information on Food Labels. Journal of Public Health. 2007; 15: 385-399.

4. Lang T Food, the Law and Public Health: Three Models of the Relationship. Public Health. 2006; 120: 30-41.

5. WHO. World Health Organisation. Global Strategy on Diet, Physical Activity and Health. WHO, Geneva, 2004.

6. MBS. Malawi Bureau of Standards. Catalogue of Malawi Standards. MBS, Blantyre, 2009.

7. MOH. Ministry of Health. Laws of Malawi: Public Health (Cap. 34:01). MOH, Lilongwe, 2004.

8. $\quad$ FAO. United Nations Food and Agriculture Organisation. Codex Guidelines on Nutrition Labelling (CAC/GL 2-1985). FAO, Rome, 2009.

9. $\quad$ FAO. United Nations Food and Agriculture Organisation. Codex Guidelines for Use of Nutrition and Health Claims (CAC/GL 23-1997). FAO, Rome, 2009.

10. FAO and WHO. United Nations Food and Agriculture Organisation and World Health Organisation. Understanding the Codex Alimentarius. $3^{\text {rd }}$ edition. FAO, Rome, 2006.

11. Mahgoub SE, Lesoli PP and K Gobotswang Awareness and Use of Nutrition Information on Food Packages among Consumers in Maseru (Lesotho). African Journal of Food, Agriculture, Nutrition and Development. 2007; 7: 1-16.

12. Nicola LW, Paterson $\mathbf{M}$ and JL Meaker What Factors Determine the Use of the Nutrition Information on the Food Label when Female Consumers from Pietermaritzburg Select and Purchase Fat Spreads? South African Journal of Clinical Nutrition. 2009.

http://www.sajcn.co.za/index.php/SAJCN/article/viewArticle/209/370 (accessed 13 June 2010). 
13. Softonic. Statistical Package for Social Scientists (SPSS) 17. http://spss.en.softonic.com (accessed 10 March 2010).

14. Parmenter K and J Wardle Development of a General Nutrition Knowledge Questionnaire for Adults. Eur J Clin Nutr. 1999; 53: 298-308.

15. Malam S, Clegg S, Kirwan S and S McGinigal Comprehension and Use of UK Nutrition Signpost Labelling Schemes. Food Standards Agency, London, 2009.

16. Nørgaard MK and K Brunsø Families' Use of Nutritional Information on Food Labels. Food Quality and Preference.2009; 20: 597-606.

17. Grunert KG, Fernaández-Celemín L, Wills JM, Bonsmann SSG and L Nureeva Use and Understanding of Nutrition Information on Food Labels in Six European Countries. Journal of Public Health. 2010. http://www.eufic.org/upl/1/default/doc/GDApaperJPubHealth.pdf (accessed 4 April 2010).

18. MOAFS. Ministry of Agriculture and Food Security. Food Security Policy. MOAFS, Lilongwe, 2006.

19. Marquis M, Dubeau C and I Thibault Canadians' Level of Confidence in their Sources of Nutrition Information. Canadian Journal of Dietetic Practice and Research. 2005; 66: 170-175.

20. Loureiro ML, Gracia A and RM Nayga Jr Do consumers Value Nutritional Labels? European Review of Agricultural Economics. 2006; 33: 249-268.

21. Singla M Usage and Understanding of Food and Nutritional Labels among Indian Consumers. British Food Journal. 2010; 112: 83-92.

22. Food Safety Promotion Board. Consumer Tracking Research: Safetrak3. Food Safety Promotion Board, Cork, 2004.

23. ACNielsen. Consumer and Nutritional Labelling: A Global Report. 2008. http://tr.nielsen.com/site/documents/nutritionalLabelingSep08_global_report (accessed 14 May 2010).

24. Drichoutis AC, Lazaridis $\mathbf{P}$ and RM Nayga $\mathbf{J r}$ Consumers' Use of Nutritional Labels: a Review of Research Studies and Issues. Academy of Marketing Science Review. 2006. http://www.amsreview.org/articles/drichoutis09-2006.pdf (accessed 24 June 2010).

25. Nayga Jr RM Towards an Understanding of Consumers' Perceptions of Food Labels. International Food and Agribusiness Management Review. 1999; 2: 29-45. 


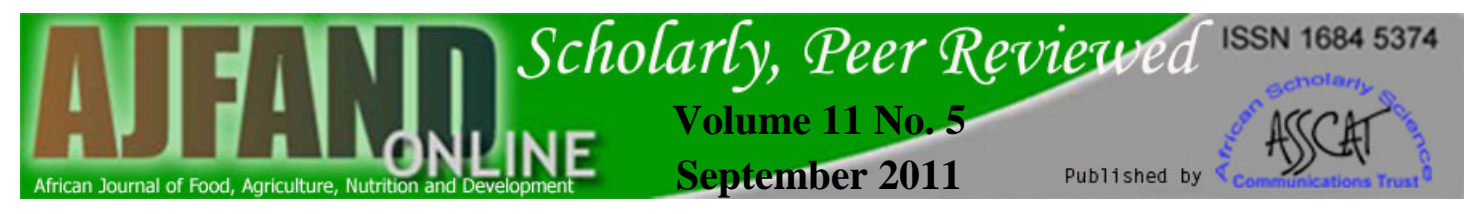

26. Satia JA, Galanko JA, Neuhouser ML and $\mathbf{K}$ Thedford Food Nutrition Label Use is Associated with Demographic, Behavioural, and Psychosocial Factors and Dietary Intake among African Americans in North Carolina. $J$ Am Diet Assoc. 2005; 105: 392-402.

27. AFIC. Asian Food Information Council. Reading Food Labels. 2008. http://thestar.com.my/health/story.asp?file=/2008/9/7/health/1954076\&sec=he alth (accessed 22 February 2010). 